\title{
Gender Differences in the Quality of Life of Patients with Liver Cirrhosis Related to Hepatitis C after Liver Transplantation
}

\author{
Tonino Bianco $^{d}$ Umberto Cillo $^{b}$ Piero Amodio ${ }^{c}$ Giacomo Zanus $^{b}$ \\ Annalisa Salari $^{d}$ Daniele Neri ${ }^{b}$ Giancarlo Bombonato ${ }^{c}$ Sami Schiff ${ }^{c}$ \\ Giovannella Baggio $^{a}$ Claudio Ronco ${ }^{e, f}$ Alessandra Brocca ${ }^{e, f}$ Sachin Soni ${ }^{f}$ \\ Lina Minazzato ${ }^{d}$ \\ a Study Center of National Health and Gender Medicine, Padua Operating Unit, ${ }^{b}$ Unit of Hepatobiliary Surgery, \\ ${ }^{\mathrm{c}}$ Department of Clinical and Experimental Medicine, and ${ }^{\mathrm{d}}$ Antalgic Therapy, Institute of Anesthesiology and \\ Reanimation, University of Padua, Padua, e Department of Nephrology, Dialysis and Transplantation, San Bortolo \\ Hospital, and ${ }^{\mathrm{f}}$ International Renal Research Institute Vicenza (IRRIV), Vicenza, Italy
}

\section{Key Words}

Gender differences · Hepatitis C - Liver transplantation ·

Pain perception · Quality of life $\cdot$ SF-36

\begin{abstract}
Background: Hepatitis C virus (HCV) infection frequently leads to chronic liver disease, which adversely affects the quality of life $(\mathrm{QoL})$ of the patient. The gender of the patient may be an important variable in the way severity of the disease is perceived. The aim of our study is to evaluate the effect of the gender variable on QoL in HCV-positive patients. Methods: This study included a total of 52 patients ( 26 men and 26 women) who completed a 1 -year follow-up after liver transplantation. QoL was assessed using the SF-36 questionnaire. Results: Male subjects have significantly higher scores on physical role functioning, bodily pain and physical activity compared with females. Females have a better QoL compared to males with regard to the emotional state and mental health. Conclusions: These results show a significant effect of the gender variable on QoL in HCV patients.
\end{abstract}

(c) 2013 S. Karger AG, Basel

\section{KARGER}

(c) 2013 S. Karger AG, Base

0253-5068/13/0364-0231\$38.00/0

E-Mail karger@karger.com

www.karger.com/bpu

\section{Introduction}

The diagnosis of chronic liver disease has important implications on the patient's life, as it often marks the beginning of frequent medical checkups and treatment. It also involves the formalities related to enrolment into the liver transplant waiting list. In addition to the clinical effects of the liver disease, the psychological stress related to the continuous monitoring and assessments can affect health-related quality of life (HRQoL).

The World Health Organization (WHO) refers to 'quality of life' as an individual's perception of their position in life in the context of the culture and value systems in which they live and in relation to their goals, expectations, standards and concerns [1]. In this sense, the HRQoL is defined as the set of physical, mental and social diseases assessed by somatic symptoms, psychological status and social interactions from the perspective of the patient, regardless of their medical condition. The international scientific community is increasingly interested in the QoL concept, particularly for the patients with chronic diseases. QoL studies can involve many different factors, ranging from the evaluation of the different effects of different diseases on daily 
activities and the identification of problems specific to each disease, to evaluate the effectiveness of different treatments and the specific factors that, in addition to patient compliance, determine treatment effectiveness.

In recent years, there have been numerous investigations on the QoL in patients with liver disease related to health, with particular attention to hepatitis $\mathrm{C}$ virus (HCV) positivity. This increased interest is justified by the significant spread of HCV in the world's population. In fact, the WHO estimated that worldwide there are about 140 million people affected by HCV, which corresponds to $2.2 \%$ of the global population. In Italy, about $2 \%$ of the general population is infected with $\mathrm{HCV}$ with a gradient that increases from north to south and the islands and with age (60\% of patients with hepatitis) [2].

Even in the absence of overt liver disease, chronic HCV compromises HRQoL, with a negative impact on both mental health and physical well-being of the patient $[3,4]$. In fact, the vast majority of HCV patients present with nonspecific symptoms, such as fatigue, irritability, general malaise, abdominal pain, joint pain and headache [5]. In most cases, medical intervention is not required, however, physical and emotional health of the patient is affected. This in turn leads to inferior HRQoL for HCV patients [6]. Even if the patient is not aware of the seriousness of the disease, his psychological state is altered [7].

\section{QoL in Patients with Liver Disease}

Several studies seem to confirm a direct adverse effect of chronic HCV on HRQoL. Some recent reviews illustrate actual prospects of research in the field of QoL in patients with chronic liver disease. In a study from Britain, 72 unselected, consecutive patients with chronic HCV were compared with 30 consecutive patients with chronic hepatitis B infection and HBsAg positivity [4]. Patients with evidence of cirrhosis were excluded. SF-36 scores were markedly reduced in patients with chronic $\mathrm{HCV}$ infection, indicating that these patients perceived themselves as unwell and they reported a significant reduction in their QoL. Other researchers have shown that a significant percentage of HCV patients suffer from fatigue [8-11]. In one of the largest studies from France, Poynard et al. [12] reported that among 1,614 patients with $\mathrm{HCV}, 53 \%$ reported fatigue at their initial visit and the fatigue was severe in $17 \%$ of these patients. This study also found that fatigue was independently associated with female gender, age $>50$ years, cirrhosis, depression and purpura. In another study, HCV patients unaware of their HCV serostatus scored signifi- cantly worse in 3 parameters of general health, vitality and mental health [13]. Those aware of their serostatus did not differ demographically, clinically, virologically or serologically from those who were unaware, nor was there a link between QoL scores and objective measures of ill health. Numerous observations suggest that HCV may exert a direct effect on HRQoL through unknown mechanisms [1416]. One possibility is that HCV may act within the central nervous system, since replicating viruses have been found within the nervous system tissue. Moreover, neuropsychiatric symptoms like fatigue, malaise, depression and cognitive impairment are among the most common complaints of patients with chronic hepatitis $\mathrm{C}$ and occur independently of liver disease or treatment status.

\section{Importance of the Gender Variable}

Over the past 30 years, medicine has reached incredible goals, including the description of the human genome, the ability to intervene at the beginning and end of life, the application of newest technologies for betterment of the patients, to name only a few. The achievements in many fields of medicine are based on evidence connected with guidelines. However, female gender has been inadequately represented in many of the epidemiological studies, which limits meaningful statistical analysis in many disorders.

The 'woman question' emerged in 1991 when Bernadine Healy, the first female director of the National Institute of American Public Health, wrote a famous editorial in the New England Journal of Medicine [17]. She coined the term 'Yentl syndrome' to highlight the gender-based disparities in the treatment and outcome of coronary artery disease in the intensive care unit (Yentl was a heroine of a Jewish story where a girl shaved her hair and disguised herself as a boy to enter religious training). Women in the intensive care unit were subjected to less diagnostic and therapeutic procedures than men and fewer invasive procedures such as cardiac catheterization and coronary artery bypass surgery $[18,19]$. Moreover, large prevention trials in patients with myocardial infarction did not include women at all. A clear discrimination by the cardiologists against the female patient was aptly emphasized. This editorial stirred basic researchers and clinicians around the world and was followed by a series of publications and studies designed to examine gender differences in various aspects of cardiovascular disease.

Another cornerstone of gender medicine was the Fourth World Conference on Women held in Peking in 
Table 1. Concepts of health according to the SF-36

\begin{tabular}{|c|c|c|c|}
\hline Physical functioning & 10 & $\begin{array}{l}\text { Very limited in performing all } \\
\text { physical activities, including } \\
\text { bathing or dressing }\end{array}$ & $\begin{array}{l}\text { Performs all types of physical activities } \\
\text { including the most vigorous without } \\
\text { limitations due to health }\end{array}$ \\
\hline $\begin{array}{l}\text { Physical role } \\
\text { functioning }\end{array}$ & 4 & $\begin{array}{l}\text { Problems with work or other daily } \\
\text { activities as a result of physical health }\end{array}$ & $\begin{array}{l}\text { No problems with work or other daily } \\
\text { activities }\end{array}$ \\
\hline Vitality & 4 & Feels tired and worn out all of the time & Feels full of pep and energy all of the time \\
\hline $\begin{array}{l}\text { Social role } \\
\text { functioning }\end{array}$ & 2 & $\begin{array}{l}\text { Extreme and frequent interference with } \\
\text { normal social activities due to physical } \\
\text { and emotional problems }\end{array}$ & $\begin{array}{l}\text { Performs normal social activities without } \\
\text { interference with physical or emotional } \\
\text { problems }\end{array}$ \\
\hline $\begin{array}{r}\text { Emotional role } \\
\text { functioning }\end{array}$ & 3 & $\begin{array}{l}\text { Problems with work or other daily } \\
\text { activities as a result of emotional problems }\end{array}$ & $\begin{array}{l}\text { No problems with work or other daily } \\
\text { activities }\end{array}$ \\
\hline
\end{tabular}

1995, where the conviction to apply the principle of gender equality in all activities, including those for health, was considered a basic human right.

In 2002, the WHO established the Department for Gender and Women's Health to recognize the differences in disease burden and treatment between men and women. In 1999, the Italian Ministry for Equal Opportunities formally established a new group with the aim of working on gender disparities in medicine through a project entitled 'A measure of health to a woman'. In 2001, a report on women's health was presented to the parliament and in 2003 a 'Guide to women's health' was published. In Italy, the attention to the gender variable is now supported by the National Center for Health and Gender Medicine. The Center aims to gather information, impart training and encourage research in all fields of medicine. It also aims to network all Italian centers interested in these issues.

With regard to QoL in patients with chronic liver disease, the gender variable is not systematically studied so far. The aim of the present study is to assess the effect of the gender variable on the subjective evaluation of QoL in patients with chronic HCV infection.

\section{Patients and Methods}

\section{SF-36 Questionnaire}

SF-36 is the best-known, patient-oriented questionnaire for the assessment of one's general health condition. This test is the short form of the Medical Outcome Study questionnaire, which was de- veloped by John Ware (the principal investigator) and his colleagues in the 1980s and was subject to successive modifications by researchers from various medical specialties [20]. The SF-36 is a generic instrument that proposes to evaluate the QoL from the patient's point of view. It is made up of 36 items divided into 8 scales (table 1) whose purpose is to evaluate the various aspects related to the patient's health and thereby furnish a global assessment of the patient's mental and physical well-being. To each question, a rough score is assigned; this initial score is further elaborated to furnish a final ranking only after evaluation of all answers given. The final response is given and the relationship between specific answers is evaluated to determine the score on each scale. Scoring on each scale is from 1 to 100 , with higher values being indicative of a better-perceived QoL relative to one's health status (fig. 1). Scoring and standard deviations will vary from scale to scale and are also dependent on age. Its validity is recognized by the international community.

\section{Patients}

This study included a total of 52 patients (26 men and 26 women) who completed a 1-year follow-up after liver transplantation. The HRQoL was assessed using the SF-36 questionnaire. The scores in the various domains of the questionnaire were compared using Student's t test. Analyses were performed using the statistical software SPSS 11.0.

\section{Results}

Male subjects have significantly higher scores on physical role functioning (daily activities or work is less impaired by physical health than in females), bodily pain (minor limitations due to pain) and physical activity (fewer constraints on the execution of physical activity in 
Fig. 1. SF-36 scores in males and females. $* \mathrm{p}<0.001$.

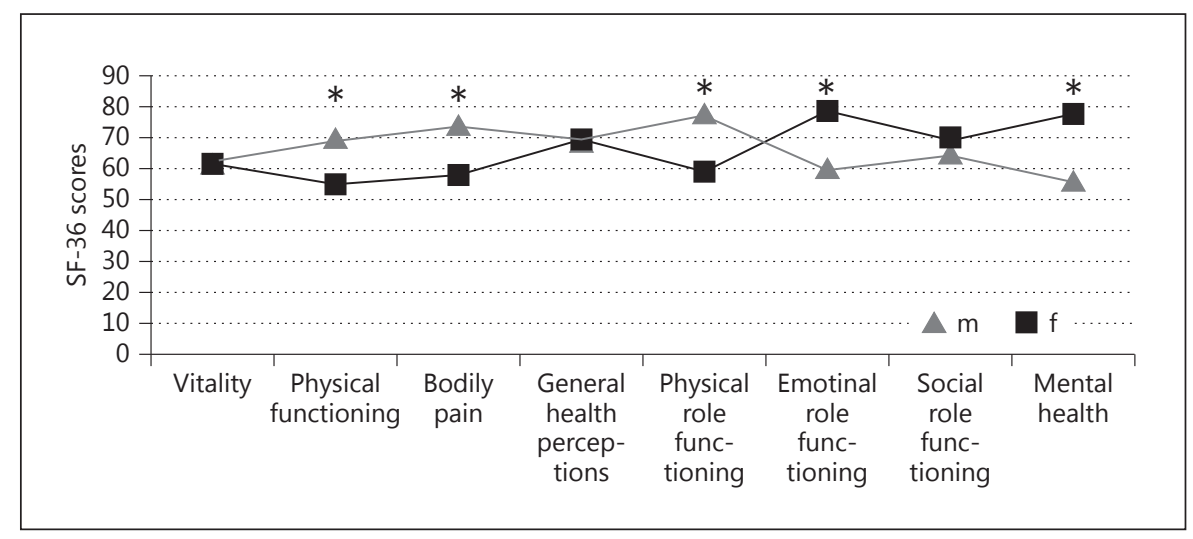

general) compared with females. On the other hand, females have a better QoL compared to males with regard to emotional role functioning (less impaired at emotional level) and mental health (self-satisfied and better mood stability).

\section{Discussion}

The way to deal with a disease and recovery will vary from person to person but there are gender differences that are often overlooked or incorrectly addressed. The significant difference between males and females with respect to 'bodily pain' may be explained by the effects of various hormones on the body. Current research shows that estrogen would increase nervous system activity; this effect manifests itself in the increased transmission of pain stimuli and pain sensitivity of women. Conversely, testosterone has an analgesic effect and can reduce pain sensitivity in men [21]. Many previous studies dealing with behavioral responses evoked by nociceptive stimuli have demonstrated an increased sensitivity of females [22].

In our study, male patients scored higher in the category of 'physical functioning' and 'physical role functioning', which are the parameters related to physical activity and perceived limitations. The female patients scored less in both parameters, suggesting impaired QoL. This may partly be explained by the effect of 'fatigue' in the posttransplant period. In an elegant cross-sectional study, van den Berg-Emons et al. [23] investigated the incidence, etiology, severity and factors of influence of fatigue in liver transplant recipients and concluded that the female gender perceives fatigue with greater severity.

In addition, sociocultural factors have to be considered. In fact, recent studies highlight the issue of gender difference in pain perception. It has been observed that for the same objective disease women report more pain than men [24]. These observations emphasize the fact that QoL assessment in liver transplant patients should not only include the clinical and biological condition of the patient but also psychosocial and cultural aspects. In this regard, it is also interesting to note that although female patients score less in the parameters 'physical functioning' and 'physical role functioning', they score better in the parameters of 'emotional role functioning' and 'mental health'. This highlights a better ability of females to manage stress and psychoemotional demands in the posttransplant setting. This could indicate differences in the ability of coping with stress between males and females of the study population.

Studies in the experience of pain in patriarchal ideology have highlighted 'the central role of etiologic and coping strategies ('being a good mother' to the female gender), suggesting that the patient needs pain to give meaning to their symptoms. It also helps to avoid negative feelings of despair and isolation. In this study, both males and females reported the common belief that a woman is better able to cope with painful events. This belief is also supported by the importance of the maternal role in women (experience of childbirth, breastfeeding, primary involvement in child rearing and emotional aspects of children) and explanations relating to the increased use of emotional expressiveness and the likelihood of seeking help and support of females. Recent studies have demonstrated sex differences in response to painful situations in teenagers and adolescents. It has been observed that males would mostly use distracting behavior while females make greater use of social support and positive self statements [25]. 
Studies on coping styles in the course of chronic diseases have shown that being active, thinking positively and expressing emotions positively correlated with significantly higher levels of functioning, with more positive scores in the clinical measures of disease and higher levels of psychological adjustment. The ability to adequately manage the transplant event and its consequences may foster greater satisfaction and improve QoL and HRQoL. In this sense, the gender differences in the QoL questionnaire identified in this study can help to direct attention to the most problematic and often neglected aspect for a patient undergoing a liver transplant by directing care and interventions in the posttransplant period in relation to an important variable such as gender.

\section{Conclusion}

HCV confers an inferior QoL to the patients. This effect is perceived by males and females in different ways.

\section{References}

1 Apolone G, Mosconi P, Ware JE Jr: Questionario sullo stato di salute SF-36. Manuale d'uso e guida all'interpretazione dei risultati. Milano, Guerini, 2000, vol 9, p 227.

2 Mele A, Tosti ME, Spada E, Mariano A, Bianco E, SEIEVA Collaborative Group: Epidemiology of Acute Viral Hepatitis: Twenty Years of Surveillance through SEIEVA in Italy and a Review of the Literature. Rapporti ISTISAN 06/12. Rome, Istituto Superiore di Sanità, 2006.

-3 Foster GR: Quality of life considerations for patients with chronic hepatitis C. J Viral Hepat 2009; 16:605-611.

-4 Foster GR, Goldin RD, Thomas HC: Chronic hepatitis $\mathrm{C}$ virus infection causes a significant reduction in quality of life in the absence of cirrhosis. Hepatology 1998;27:209-212.

$\checkmark 5$ Marcellin P: Hepatitis C: the clinical spectrum of the disease. J Hepatol 1999;31(suppl 1):916.

-6 Strauss E, Dias Teixeira MC: Quality of life in hepatitis C. Liver Int 2006;26:755-765.

$>7$ Farrell C, Brearley SG, Pilling M, Molassiotis A: The impact of chemotherapy-related nausea on patients' nutritional status, psychological distress and quality of life. Support Care Cancer 2013;21:59-66.

$>8$ Tong MJ, el-Farra NS, Reikes AR, Co RL: Clinical outcomes after transfusion-associated hepatitis C. N Engl J Med 1995;332:14631466.

9 Kenny-Walsh E: Clinical outcomes after hepatitis $\mathrm{C}$ infection from contaminated anti-D immune globulin. Irish Hepatology Research Group. N Engl J Med 1999;340:1228-1233.
10 Abdo AA: Hepatitis C and poor quality of life: is it the virus or the patient? Saudi J Gastroenterol 2008;14:109-113.

11 Barkhuizen A, Rosen HR, Wolf S, Flora K, Benner K, Bennett RM: Musculoskeletal pain and fatigue are associated with chronic hepatitis C: a report of 239 hepatology clinic patients. Am J Gastroenterol 1999;94:13551360.

12 Poynard T, Cacoub P, Ratziu V, Myers RP, Dezailles MH, Mercadier A, Ghillani P, Charlotte F, Piette JC, Moussalli J: Fatigue in patients with chronic hepatitis C. J Viral Hepat 2002;9:295-303.

13 Rodger AJ, Jolley D, Thompson SC, Lanigan A, Crofts N: The impact of diagnosis of hepatitis $\mathrm{C}$ virus on quality of life. Hepatology 1999;30:1299-1301.

14 Forton DM, Thomas HC, Taylor-Robinson SD: Central nervous system involvement in hepatitis $\mathrm{C}$ virus infection. Metab Brain Dis 2004;19:383-391.

15 Forton DM, Hamilton G, Allsop JM, Grover VP, Wesnes K, O’Sullivan C, Thomas HC, Taylor-Robinson SD: Cerebral immune activation in chronic hepatitis $\mathrm{C}$ infection: a magnetic resonance spectroscopy study. J Hepatol 2008;49:316-322.

16 Bagaglio S, Cinque P, Racca S, Pedale R, Grasso MA, Lazzarin A, Morsica G: Hepatitis C virus populations in the plasma, peripheral blood mononuclear cells and cerebrospinal fluid of HIV/hepatitis C virus-co-infected patients. AIDS 2005;19(suppl 3):S151-S165.

17 Healy B: The Yentl syndrome. N Engl J Med 1991;325:274-276.
18 Ayanian JZ, Epstein AM: Differences in the use of procedures between women and men hospitalized for coronary heart disease. N Engl J Med 1991;325:221-225.

19 Steingart RM, Packer M, Hamm P, Coglianese ME, Gersh B, Geltman EM, Sollano J, Katz S, Moye L, Basta LL, et al: Sex differences in the management of coronary artery disease. Survival and Ventricular Enlargement Investigators. N Engl J Med 1991;325:226230.

20 Ware JE Jr: SF-36 health survey update. Spine (Phila Pa 1976) 2000;25:3130-3139.

21 Aloisi AM: Gonadal hormones and sex differences in pain reactivity. Clin J Pain 2003;19: 168-174.

22 Paller CJ, Campbell CM, Edwards RR, Dobs AS: Sex-based differences in pain perception and treatment. Pain Med 2009;10:289-299.

23 van den Berg-Emons R, Kazemier G, van Ginneken B, Nieuwenhuijsen C, Tilanus H, Stam $\mathrm{H}$ : Fatigue, level of everyday physical activity and quality of life after liver transplantation. J Rehabil Med 2006;38:124-129.

24 Robinson ME, George SZ, Dannecker EA, Jump RL, Hirsh AT, Gagnon CM, Brown JL: Sex differences in pain anchors revisited: further investigation of 'most intense' and common pain events. Eur J Pain 2004;8:299-305.

25 Robinson ME, Gagnon CM, Dannecker EA, Brown JL, Jump RL, Price DD: Sex differences in common pain events: expectations and anchors. J Pain 2003;4:40-45. 